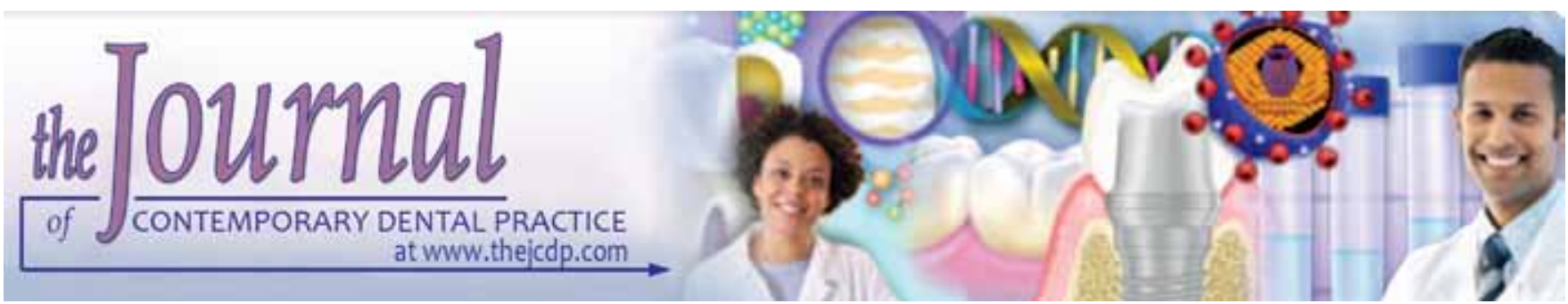

\title{
Role of Prophylactic Antibiotics in the Management of Postoperative Endodontic Pain
}

\author{
${ }^{1}$ Leena Alsomadi, ${ }^{2}$ Riyad Al Habahbeh
}

\begin{abstract}
Aim: To investigate the efficacy of using antibiotics in post endodontic treatment as a method to alleviate post-treatment pain.
\end{abstract}

Materials and methods: After completion of endodontic treatment 129 patients were randomly divided into two groups: Group A (65 patients) received Ibuprofen $400 \mathrm{mg}$ one tablet before procedure and one tablet every 8 hours for the first day, then one tablet once indicated by pain. Group B (64 patients) received the same regimen as group $A$ in addition to amoxicillin, clavulanic acid tablets (one tablet before the procedure, and then one tablet twice daily for a total of 3 days). Intensity of pain at 8 hours interval using visual analog scale (VAS) and total number of Ibuprofen tablets used was recorded by patients.

Results: Peak postoperative pain occurred at 16 hours posttreatment in both groups, there was a significant difference in the pain scale between the two groups in favor for group $B$ over group $A$ (3.8 vs 2.1 respectively). Pain scale was significantly lower in group B at 24, 32, 40, and 48 hours post-treatment with a $p$-value of $<0.05$. The pain scale at 56,64 and 72 hours were also less in group $B$, although could not show up as statistical difference. Patients in group A used statistically significant more Ibuprofen than patients in group B (486 vs 402).

Conclusion: Antibiotic prescription to manage post endodontic treatment pain results in less pain with less consumption of Ibuprofens.

Clinical significance: Pain management in endodontics is a real challenge, nonsteroidal anti-inflammatory drugs (NSAIDS) are used effectively in many patients to alleviate post endodontic pain. Nonsteroidal anti-inflammatory drugs may have adverse reactions or may be contraindicated. Short-term

\footnotetext{
${ }^{1}$ Department of Conservative Dentistry, University of Jordan Amman, Jordan

${ }^{2}$ Department Conservative Dentistry, Royal Medical Services Amman, Jordan

Corresponding Author: Leena Alsomadi, Associate Professor Department of Conservative Dentistry, University of Jordan PO Box 830453, Amman, Jordan, Phone: 009626797728100 e-mail: alsomadi@yahoo.com
}

use of antibiotics to alleviate pain can be of clinical benefits in these patients.

Keywords: Antibiotics, Endodontic treatment, Pain, Randomized clinical trial.

How to cite this article: Alsomadi L, Al Habahbeh R. Role of Prophylactic Antibiotics in the Management of Postoperative Endodontic Pain. J Contemp Dent Pract 2015;16(12):939-943.

Source of support: Nil

Conflict of interest: None declared

\section{INTRODUCTION}

Persistent pain associated with teeth after nonsurgical or surgical endodontic treatment has been used as an indicator of treatment failure. ${ }^{1,2}$ Pain management in dentistry can be a real challenge. The key in managing pain lies in understanding whether what you do to patients will or will not create an inflammatory response, which is what activates the pain-producing mediators in tissue. Generally, procedures on hard tooth structure that do not involve the pulp create little or no inflammatory response, but when soft tissues are traumatized, a pain response can be expected. ${ }^{3}$

Alleviating pain is of the utmost importance when treating dental patients, as it is prevalent and has farreaching implications, for both the patient and the clinician. ${ }^{4}$ The major cause of pain is thought to be the release of inflammatory mediators that activate sensory nociceptors surrounding the tooth. ${ }^{5}$ The resultant stimulation of both central and peripheral mechanisms ${ }^{6}$ is referred to as hyperalgesia and defined as an increase in perceived magnitude of a painful stimulus. ${ }^{7}$ Given that, the mechanisms involved are occurring at the periphery, an anti-inflammatory agent should be used to control this process.

Apical periodontitis should be considered as an inflammatory reaction in the periapical tissues to the presence of bacteria within the root canal system. ${ }^{8,9}$ It 
is evident that an infected root canal system is a unique niche for the selective species of microorganisms. ${ }^{10}$

The composition of microflora of root canals has been the focus of considerable research over the years. Results of studies clearly defined the microbial differences between primary endodontic treatment and retreatment. ${ }^{11}$ Apical periodontitis persisting after root canal treatment presents a more complex etiological and therapeutic situation. $^{12}$

Infection will definitely aggravate the inflammatory reaction that increasing the milieu of inflammatory mediators causing post-treatment pain.

Use of antibiotics post endodontic treatment as a method to alleviate post-treatment pain will be evaluated and tested in this interventional prospective comparative study.

\section{MATERIALS AND METHODS}

The study was performed in consultant endodontic clinic at the conservative dentistry department of King Hussein Medical Centre over 4 months period (April 2015-August 2015).

One hundred seventy-one patients were referred for endodontic treatment to the clinic during the study time, 149 agreed to participate in this study. Patients aged 18 to 62 years old from both gender. The study was approved by Ethics Committee of the hospital and a written consent was provided from each participant after an informed consultation session done by one of the residents working in the clinic.

A standard questionnaire was used to record their demographic information including age, gender, weight and height, medical illness, and allergy to drugs.

All patients were anesthetized using Ubistesin Forte ( $4 \%$ articaine Forte $3 \mathrm{M}$ ESPE $1 \mathrm{ml}$ injection contains $40 \mathrm{mg}$ Articaine hydrochloride and $0.012 \mathrm{mg}$ epinephrine hydrochloride). After securing proper rubber dam isolation access cavity was performed and thorough cleaning and shaping was done using step down technique. Protaper next rotary system (Dentsply Maillefer/ Ballaigues Switzerland) was used for shaping the canals. Sodium hypochlorite (2.25\%) was used as an irrigation solution followed by $17 \%$ ethylenediaminetetra-acetic acid (EDTA) solution. A size $10 \mathrm{~K}$-file was used for patency of the apical foramen. All canals were dried and filled using vertical compaction technique in a single visit approach except for three cases we could not get dry canals calcium hydroxide used as an intracanal medicament, these cases were excluded from the study in order to standardize the treatment procedure.

The patients were randomly divided before the start of treatment into two groups. Group A received Ibuprofen 400 mg (Balkaprofen 400 mg , Hikma Pharmaceutical
Co, Jordan ), one tablets before procedure and one tablet every 8 hours for the first day, then one tablets once indicated by pain with a maximum of 3 tablets per day for maximum of 3 days post procedure. Group $B$ received the same regimen as group A (Ibuprofen $400 \mathrm{mg}$ tablets) with the same dosage in addition to amoxicillin, clavulanic acid tablets (Amoclan Forte 625 mg Tab, Hikma Pharmaceutical Co, Jordan) one tablet before the procedure, and then one tablet twice daily for a total of 3 days.

In addition to the abovementioned cases which were excluded due to procedural variation, exclusion criteria for the enrollment in the study were any known allergy to drugs, bronchial asthma, active peptic ulcer diseases, pregnancy or breastfeeding, coagulation disorders, kidney impairment, or liver impairment.

A total of 129 patients were enrolled in the study after exclusion of 20 patients for one or more reasons from the abovementioned exclusion criteria.

The patients were randomized into two group using schemes sequentially numbered opaque sealed envelopes (SNOSE) 65 in group A, and 64 in group B.

All patients were asked to complete a form to record the intensity of pain at 8 hours interval and to record the number of Ibuprofen tablets used everyday, and any side effects experienced during the treatment period. The pain was measured on a standard of $100 \mathrm{~mm}$ visual analog scale (VAS) $(0=$ no pain, $100=$ worst pain ever $)$.

All forms were collected from patients in the followup visit 5 days after procedure.

Three patients from group $\mathrm{A}$ and two patients from group B did not complete the forms, one from group B because of severe gastroenteritis attributed to the use of antibiotic, and all other four were due to unknown causes. CONSORT Flow Chart 1 shows the recruitment of the participates.

Flow Chart 1: The recruitment of participants

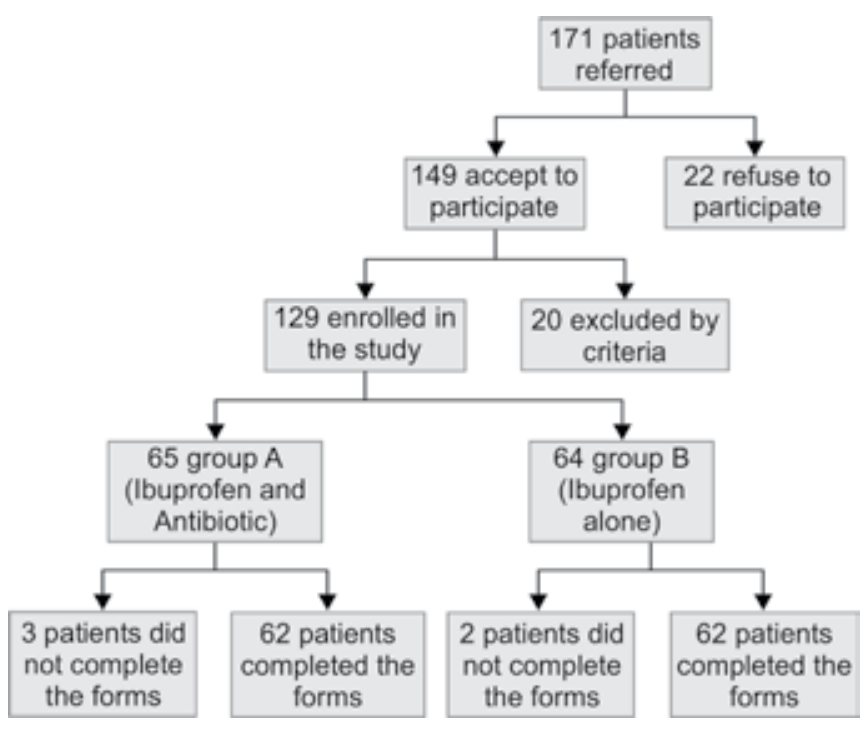


Statistical analysis was performed using statistical package for the social science (SPSS 20.0) for Windows (SPSS Inc., Chicago, IL, USA). Demographic data were analyzed using $\times 2$ tests and Analysis of variance (ANOVA). To compare the two groups regarding pain intensity repeated measures ANOVA tests were used and student's t-tests for independent samples. The rescue medication intake variable was analyzed using t-tests. The level of significance was set at $\mathrm{p}<0.05$.

\section{RESULTS}

The study groups showed no difference regarding gender, age, weight, medical illness or allergy to drug (Table 1).

The preoperative pain expressed by the VAS scale was not significantly different between the two groups. For the postoperative pain, the peak pain occurred at 16 hours post-treatment in both groups, although there was a significant difference in the pain scale between the two groups in favor for group B over group A (3.8 vs 2.1 respectively). For the first 8 hours post-treatment patients in group A experienced less pain than in group B which did not show a statistical difference with a p-value of 0.82 . Pain scale was significantly lower in group B at 24, 32, 40, and 48 hours post-treatment with a p-value of less than 0.05 . The VAS scale in each group in these time intervals are shown in Table 2.

This statistical difference in pain scale disappeared at 56,64 and 72 hours although the pain scale was less in group $B$, the $p$-value for these intervals were $0.22,0.72$ and 0.66 respectively.

The two groups were comparable when side effect of drugs are studied, there was no statistical difference in both groups in regard to nausea, vomiting, diarrhea, rash, and gastric pain as shown in Table 3.

When the need to use the nonsteroidal antiinflammatory drug (Ibuprofen $400 \mathrm{mg}$ ) was studied as expressed by the total number tablets used by all patients in each group, patients in group A used statistically significant more Ibuprofen than patients in group B (486 vs 402 respectively with a p-value of 0.001 ).

Table 1: Demographic data

\begin{tabular}{llll}
\hline & Group A & Group B & $p$-value \\
\hline Number of patients & 62 & 62 & \\
Age (years) & $36.7 \pm 7.5$ & $34.5 \pm 6.9$ & 0.1231 \\
Male/Female $^{* *}$ & $22 / 40$ & $24 / 38$ & 0.6855 \\
${\text { Weight }(\mathrm{Kg})^{*}}_{\text {History of medical }}$ & $64.3 \pm 9.12$ & $67 \pm 8.9$ & 0.1164 \\
He & 5 & 0.3632
\end{tabular}

illness necessitate medications $^{* *}$

$\begin{array}{llll}\text { Allergy to drugs }^{* *} & 1 & 2 & 0.0126\end{array}$

*Data presented as mean \pm standard deviation for age and weight where statistical analysis was done using unpaired $t$ test for age and weight; **Numbers were used for gender, medical history and allergy and Fisher's exact test were used for statistical analysis
Table 2: Intensity of pain at different time intervals, the pain was measured on a standard of $100 \mathrm{~mm}$ VAS $(0=$ no pain, $100=$ worst pain ever)

\begin{tabular}{lllll}
\hline & \multicolumn{2}{l}{ Mean \pm standard deviation } & & (t) student \\
& Group $A$ & Group $B$ & $p$-value & \\
\hline Pain at T1 & $6.4 \pm 1.3$ & $5.9 \pm 1.8$ & 0.92 & \\
Pain at T2 & $1.13 \pm 1.56$ & $1.19 \pm 1.52$ & 0.82 & \\
Pain at T3 & $3.8 \pm 0.6$ & $2.1 \pm 0.4$ & $0.0001^{*}$ & \\
Pain at T4 & $2.58 \pm 2.49$ & $2.42 \pm 2.09$ & $0.001^{*}$ & \\
Pain at T5 & $2.40 \pm 0.70$ & $1.9 \pm 0.70$ & $0.0001^{*}$ & \\
Pain at T6 & $1.85 \pm 0.89$ & $1.54 \pm 0.77$ & $0.001^{*}$ & \\
Pain at T7 & $1.75 \pm 0.67$ & $1.55 \pm 0.81$ & $0.001^{*}$ & \\
Pain at T8 & $1.58 \pm 3.11$ & $1.50 \pm 2.04$ & 0.22 & \\
Pain at T9 & $1.66 \pm 3.23$ & $1.44 \pm 2.44$ & 0.72 & \\
Pain at T10 & $0.67 \pm 1.04$ & $0.59 \pm 1.05$ & 0.60 & \\
T1: Before & T2: $: 8$ hours & T3: 16 & T4: 24 & T5:32 \\
treatment & post-treatment & hours PT & hours PT & hours PT \\
& (PT) & & & \\
T6: 40 & T7: 48 hours & T8: 56 & T9: 64 & T10: 72 \\
hours PT & PT & hours PT & hours PT & hours PT \\
\hline
\end{tabular}

*p-value with statistically significant difference

Table 3: Side effects experienced during the treatment period and the total number of Ibuprofen tablets used as recorded by patients in groups $A$ and $B$

\begin{tabular}{llll}
\hline Side effect & $\begin{array}{l}\text { Number of } \\
\text { patient } \\
\text { (group A) }\end{array}$ & $\begin{array}{l}\text { Number of } \\
\text { patient } \\
\text { (group B) }\end{array}$ & p-value \\
\hline Nausea & 13 & 14 & 0.53 \\
Vomiting & 11 & 10 & 0.71 \\
Diarrhea & 3 & 5 & 0.66 \\
Rash & 1 & 2 & 0.28 \\
Gastric pain & 6 & 4 & 0.47 \\
$\begin{array}{l}\text { Total number of } \\
\text { Ibuprofen tablets taken } \\
\text { by all patients }\end{array}$ & 486 & 402 & $0.001^{*}$ \\
\hline
\end{tabular}

* $p$-value with statistically significant difference

\section{DISCUSSION}

Nonsteroidal anti-inflammatory drugs (NSAIDs) are used in treatment of pain including tooth pains for many years. ${ }^{13}$ Even though they are effective in relief of pain, they may have adverse reactions..$^{13}$ Because of almost serious digestive problems of NSAID medicines, dentists and patients might have some concerns although having a high efficiency to be used as the first level of treatment for postoperative endodontic procedures.

As general role, In the absence of signs and symptoms of infection, medical practitioners should refrain from prescribing antibiotics as a means of relieving pain, ${ }^{14}$ however, many dentist are still using antibiotics without clear indications, e.g. 80.6\% dental practitioners in Shiraz/ Iran prescribed antibiotics, ${ }^{15}$ whereas Palmer et al showed that $12.5 \%$ of British GDPs prescribed antibiotics. ${ }^{16}$ Another two studies conducted in the USA showed approximately $16 \%$ antibiotic prescription, ${ }^{17,18}$ however, 
one study had only surveyed endodontic specialists ${ }^{17}$ which was similar to Gatewood et al In $1990,{ }^{18}$ another study conducted in Yazd on GDP prescription habits found much lower rate of unnecessary prescription $(13.84 \%){ }^{19}$

Antibiotics prescription for pain management was tested in few studies before, none of them showed improvement on post endodontic treatment pain when using systemic antibiotics. Mark et $\mathrm{al}^{20}$ reported that administration of systemic penicillin postoperatively did not significantly reduce pain, percussion sensitivity or swelling. Keenan et $\mathrm{a}^{21}$ also found no significant differences in pain relief for patients with untreated irreversible pulpitis who received antibiotics and those who did not. Rehman et al also showed that antibiotics make no difference regarding the occurrence of postoperative pain. ${ }^{22}$

Our study showed different results where the pain was similar in the two groups in the first 8 hours, but the pain was less thereafter, where patients who received antibiotics experience less pain, we think that this might be explained by the fact that endodontic treatments can be associated with dissemination of infection to the surrounding tissue after the first 8 hours with the beneficial effect of systemic antibiotics. This assumption is supported by earlier reports which suggest that the failure to prescribe antibiotics to patients undergoing endodontic therapy not only increases potential flare-up, but might also lead to the exposure of potentially dangerous bacteria that are responsible for serious infections, such as continuous bacteremia and septicemias, septic embolization, deep-space cellulitis, intracranial abscesses and Ludwig's angina. ${ }^{23-25}$ This flare-up was suggested by Pickenpaugh et al as manifested by schedules of pain assessment to occur 12 to 48 hours following treatment and lasts at least 48 hours. $^{26}$

Microbiological status at the time of root filling has been claimed to affect the healing process in endodontic treatment with better healing observed in those with a negative bacterial sample ${ }^{27,28}$ which support the better pain control in treated group with antibiotic as a results of possible faster and more healing. This contamination with microbiological organisms has been confirmed by many epidemiological studies were despite treatment was usually conducted under well-controlled conditions at teaching institutions or specialist clinics. These studies report a high prevalence of apical periodontitis associated with root-filled teeth. ${ }^{29-32}$ Around one in every three rootfilled teeth shows signs of apical periodontitis.

In a recent publication by Iftikhar $\mathrm{Akbar}^{33}$ a single dose of $2 \mathrm{gm}$ amoxicillin 1 hour before the first visit of root canal treatment was compared to no treatment showed
A higher percentage of flare-up (12\%) in control group compare to $(8 \%)$ in the experimental group. However, the difference was not statistically significant.

The failure to demonstrate benefit from previous studies as well as the most recent study by Akbar in contrast to ours might be explained by the duration of treatment which is extended to 3 days in our protocol which might have longer coverage of antimicrobial activity to prevent flare-up caused by local infection aggravated by manipulation and instrumentation on top of pre-exciting bacterial milieu.

Our results shows potential benefit of extended antibiotic prescription after endodontic treatment to manage post-treatment pain, although our results will need to be validated by larger comparative study.

\section{CONCLUSION}

Antibiotic prescription to manage post endodontic treatment pain results in less pain with less consumption of Ibuprofens. Our results will need to be validated by larger comparative study.

\section{CLINICAL SIGNIFICANCE}

Pain management in endodontics is a real challenge, NSAIDS are used effectively in many patients to alleviate post endodontic pain. Non-steroidal antiinflammatory drugs may have adverse reactions or may be contraindicated. Short-term use of antibiotics to alleviate pain can be of clinical benefits in these patients.

\section{REFERENCES}

1. Hoskinson SE, Ng Y-L, Moles D, Hoskinson AE, Gulabivala K. Comparison of outcome or root canal treatment using two different protocols. Oral Surg Oral Med Oral Pathol Oral Radiol Endod 2002;93:705-715.

2. Rahbaran S, Gilthorpe MS, Harrison SV, Gulabivala K. Comparison of clinical outcome of periapical surgery in endodontic and oral surgery units of a teaching dental hospital: a retrospective study. Oral Surg Oral Med Oral Pathol Endod 2001;91:700-709.

3. Menhinick KA, Gutmann JL, Regan JD, Taylor SE, Buschang PH. The efficacy of pain control following nonsurgical root canal treatment using ibuprofen or a combination of ibuprofen and acetaminophen in a randomized, double-blind, placebo-controlled study. Int Endod J 2004;37(8):531-541.

4. Matthew JD. Pain management for dentists. TFDA 2008;8: 33-37.

5. Johnsen DC, Harshbarger J, Rymer HD. Quantitative assessment of neural development in human premolars. AnatRec 1983;205:421-429.

6. Malmberg AB, Yaksh TL. Hyperalgesia mediated by spinal glutamate or substance $\mathrm{P}$ receptor blocked by spinal cyclooxygenase inhibition. Science 1992;257:1276-1279.

7. Dubner R, Bennett GJ. Spinal and trigeminal mechanisms of nociception. Annu Rev Neurosci 1983;6:381-418. 
8. Kakehashi S, Stanley H, Fitzgerald R. The effect of surgical exposures of dental pulps in germ-free and conventional laboratory rats. Oral Surg Oral Med Oral Pathol 1965; 20:340.

9. Sundqvist G. Bacteriologic studies of necrotic pulps [Thesis]. Umea University (Sweden); 1976.

10. Fabricius L. Oral bacteria and apical periodontitis: an experimental study in monkeys [Thesis]. University of Goteborg (Sweden); 1982.

11. Sundqvist G, Figdor D. Life as an endodontic pathogen. Etiological differences between untreated and root-filled root canals. Endod Top 2003;6:3-28.

12. Nair PRN, Sjogren U, Kahnberg KE, Krey G, Sundqvist G. Intraradicular bacteria and fungi in root-filled, asymptomatic human teeth with therapy-resistant periapical lesions: a longterm light and electron microscopic follow-up study. J Endod 1990;16(12):580-588.

13. Klasser GD, Epstein J. Nonsteroidal anti-inflammatory drugs: confusion, controversy and dental implications. J Can Dent Assoc 2005;71:575-580.

14. Abbott PV. Selective and intelligent use of antibiotics in endodontics. Aust Endod J 2000;26:30-39.

15. Nabavizadeh M, Sahebi S, Nadian I. Antibiotic prescription for endodontic treatment: general dentist knowledge + practice in Shiraz. Iranian Endod J 2011;6(2):54-59.

16. Palmer NA, Dailey YM, Martin MV. Can audit improve antibiotic prescribing in general dental practice? Br Dent J 2001;191:253-255.

17. Yingling NM, Byrne BE, Hartwell GR. Antibiotic use by members of the American Association of Endodontists in the year 2000: report of a national survey. J Endod 2002;28: 396-404.

18. Gatewood RS, Himel VT, Dorn SO. Treatment of the endodontic emergency: a decade later. J Endod 1990;16:284-291.

19. Tabrizizade M, Alijani T. Antibiotic prescribing habits among general dental practitioners in yazd. J Islamic Dental Association Iran 2005;17:23-29.

20. Mark H, Al Reader, Mike B. Effect of penicillin on postoperative endodontic pain and swelling in symptomatic necrotic teeth. J Endod 2001;27:117-123.

21. Keenan JV, Farman AG, Fedorowicz Z, Newton JT. A Cochrane systematic review finds no evidence to support the use of antibiotic for pain relief in irreversible pulpitis. J Endod 2006;32:87-92.

22. Rehman K, Akber I, Qazi J. Role of antibiotics in control of post-endodontic pain: cases of symptomatic irreversible pulpitis and periapical periodontitis: a randomized control clinical trial. J Khyber College Dentistry 2012;3(1):12-16.

23. Abbott AA, Koren LZ, Morse DR, Sinai IH, Doo RS, Furst ML. A prospective randomized trial on efficacy of antibiotic prophylaxis in asymptomatic teeth with pulpal necrosis and associated pericapical pathosis. Oral Surg Oral Med Oral Pathol 1988;66:722-733.

24. Morse DR, Furst ML, Belott RM, Lefkowitz RD, Spritzer IB, Sideman BH. Infectious flare-ups and serious sequelae following endodontic treatment: a prospective randomized trial on efficacy of antibiotic prophylaxis in cases of asymptomatic pulpal-periapical lesions. Oral Surg Oral Med Oral Pathol 1987;64(1):96-109.

25. Morse DR, Furst ML, Lefkowitz RD, D'Angelo D, Esposito JV. A comparison of erythromycin and cefadroxil in the prevention of flare-ups from asymptomatic teeth with pulpal necrosis and associated periapical pathosis. Oral Surg Oral Med Oral Pathol 1990;69:619-630.

26. Pickenpaugh L, Reader A, Beck M, Meyers WJ, Peterson LJ. Effect of prophylactic amoxicillin on endodontic flare-up in asymptomatic, necrotic teeth. J Endodontics 2001; 27(1):53-56.

27. Molander A, Warfvinge J, Reit C, Kvist T. Clinical and radiographic evaluation of one- and two-visit endodontic treatment of asymptomatic necrotic teeth with apical periodontitis: a randomized clinical trial. J Endod 2007;33:1145-1148.

28. Sjögren U, Figdor D, Persson S, Sundqvist G. Influence of infection at the time of root filling on the outcome of endodontic treatment of teeth with apical periodontitis. Int Endod J 1997;30:297-306.

29. Allard U, Palmqvist S. A radiographic survey of periapical conditions in elderly people in a Swedish county population. Endod Dent Traumatol 1986;2:103-108.

30. Bergenholtz G, Malmcrona E, Milthon R. (Endodontic treatment and periapical state. Part I. Radiographic study of frequency of endodontically treated teeth and frequency of periapical lesions). Tandläkartidningen 1973;65:64-73.

31. Bergström J, Eliasson S, Ahlberg KF. Periapical status in subjects with regular dental care habits. Community Dent Oral Epidemiol 1987;15:236-239.

32. Frisk F, Hakeberg M. A 24-year follow-up of root filled teeth and periapical health amongst middle aged and elderly women in Goteborg, Sweden. Int Endod J 2005;38:246-254.

33. Iftikhar Akbar. Efficacy of prophylactic use of antibiotics to avoid flare up during root canal treatment of non vital teeth: a randomized clinical trial. J Clinical Diagnostic Research 2015;9(3):ZC08-ZC11. 